\title{
ABSTRACT \\ PROFESSIONAL DEVELOPMENT IN SCHOOLS: PREDICTORS OF EFFECTIVENESS AND IMPLICATIONS FOR STATEWIDE PBIS TRAININGS
}

\author{
by Katelyn Palmer
}

\begin{abstract}
Research has identified several factors that contribute to the effectiveness of professional development opportunities in schools including improvement of participants' knowledge, administrator support, incorporation of active learning activities, duration, fostering coherence, and timing. The current study examined how these six factors contribute to the effectiveness of PBIS trainings conducted in Ohio. More specifically, this study examined a) whether there is a relationship between each of these six factors and the effectiveness of these training sessions and b) identified the combination of factors that best predicts the effectiveness of these training sessions through multinomial regression analysis. Results revealed the effectiveness of the trainings to be significantly related to incorporation of active learning, level of coherence between learning activities at the training and structures currently in place at participants' schools, increase in knowledge, and date of training. Implications for future PBIS trainings and professional development events in general are discussed.
\end{abstract}


PROFESSIONAL DEVELOPMENT IN SCHOOLS: PREDICTORS OF EFFECTIVENESS AND IMPLICATIONS FOR STATEWIDE PBIS TRAININGS

\author{
Thesis Report \\ Submitted to the \\ Faculty of Miami University \\ in partial fulfillment of \\ the requirements for the degree of \\ Educational Specialist (Ed.S.) \\ by \\ Katelyn Palmer \\ Miami University \\ Oxford, Ohio \\ 2017 \\ Advisor: Dr. Amity Noltemeyer \\ Reader: Dr. Dawna Cricket Meehan \\ Reader: Dr. Mary Peters
}

(C)2017 Katelyn Palmer 
This thesis report titled

\title{
PROFESSIONAL DEVELOPMENT IN SCHOOLS: PREDICTORS OF EFFECTIVENESS AND IMPLICATIONS FOR STATEWIDE PBIS TRAININGS
}

by

\author{
Katelyn Palmer \\ has been approved for publication by \\ The School of Education, Health and Society \\ and \\ Department of Educational Psychology
}

Dr. Amity Noltemeyer

Dr. Dawna Cricket Meehan

Dr. Mary Peters 


\section{Table of Contents}

List of Tables........................................................................................................................................... iv

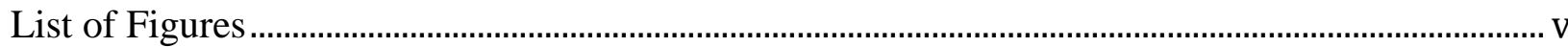

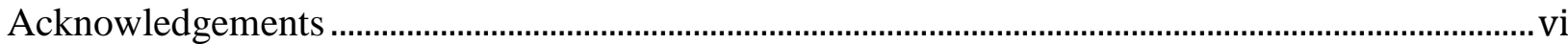

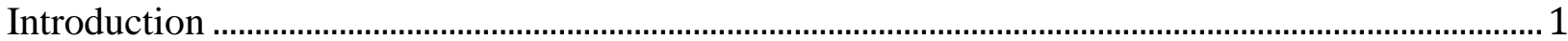

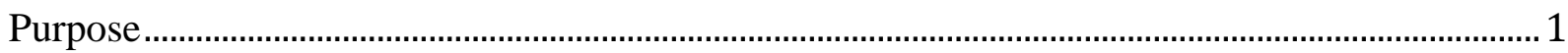

Defining Professional Development.............................................................................................. 3

Purpose of Professional Development in Schools ........................................................................... 4

Factors Influencing the Effectiveness of Professional Development ............................................. 5

Present Study and Hypotheses ......................................................................................................... 11

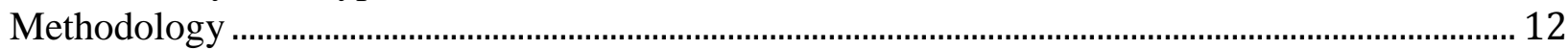

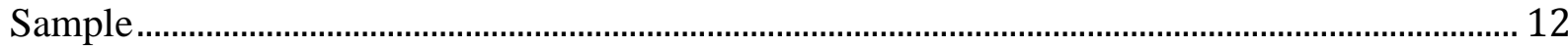

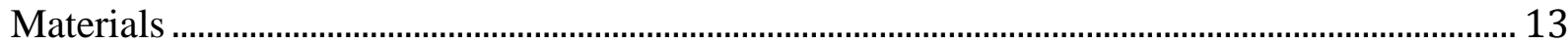

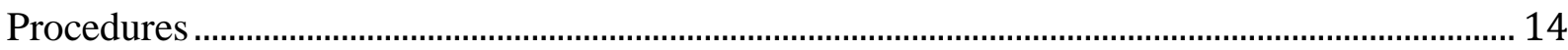

Data Analysis ...................................................................................................................... 14

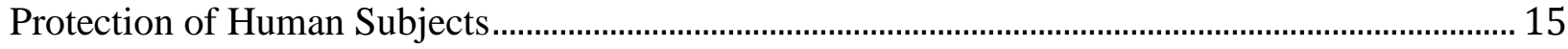

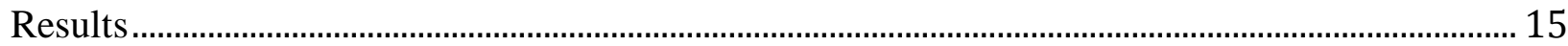

Multinomial Regression ....................................................................................................... 18

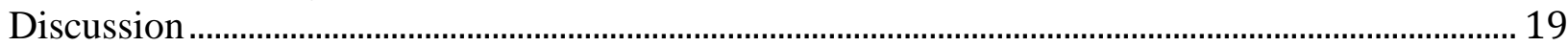

Implications for Future Trainings........................................................................................ 20

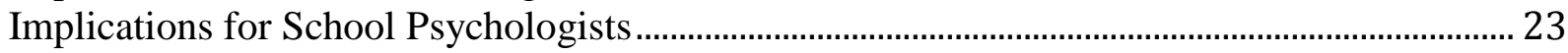

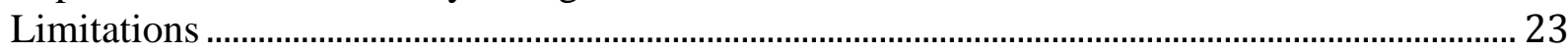

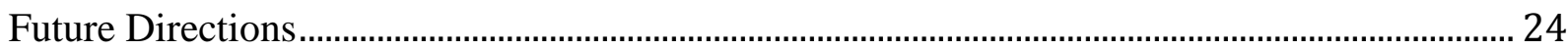

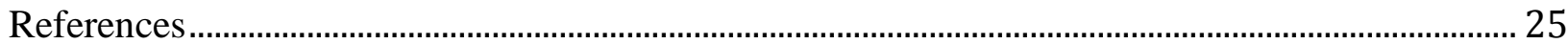

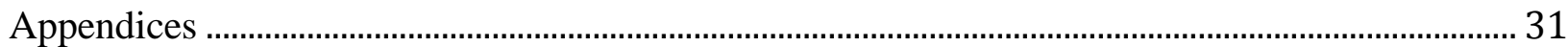




\section{List of Tables}

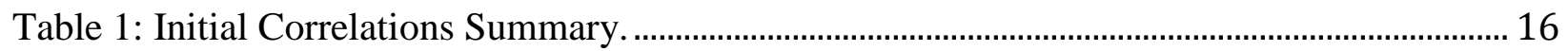




\section{List of Figures}

Figure 1: Role of Attendees............................................................................................................ 13

Figure 2: Grade Levels Attendees Serve. ………………………………………………………….. 13 


\section{Acknowledgements}

I would like to sincerely thank my thesis advisor, Dr. Amity Noltemeyer, for all of the guidance and support she provided as this project was completed. Additionally, I would like to thank my other committee members, Dr. Cricket Meehan and Dr. Mary Peters for taking the time to review my work and provide helpful feedback. I appreciated having the opportunity to learn from them. Next, I would like to thank my parents for their overwhelming amount of support as I pursued higher education. Finally, I would like to thank staff from the Ohio Department of Education, State Support Teams, School Climate Transformation Grant, and Ohio PBIS Network for their instrumental role in Ohio PBIS training and data collection.

\section{Disclaimer:}

The data reported in this thesis were collected in part under a grant from the Department of Education. However, those contents do not necessarily represent the policy of the Department of Education, and you should not assume endorsement by the Federal Government. 


\section{Introduction}

\section{Purpose}

Historically, school-wide discipline has primarily been reactionary in nature (Positive Behavioral Interventions \& Supports OSEP Technical Assistance Center, 2016b). In other words, school discipline has mainly focused on responding to student misbehavior using various forms of punishment such as reprimands, privilege loss, office referrals, suspensions, and expulsions. However, research suggests implementing punishment-based strategies is ineffective, and this is especially true when these punishment-based strategies are used inconsistently and in the absence of other positive strategies (Positive Behavioral Interventions \& Supports OSEP Technical Assistance Center, 2016b).

As a result, schools have been increasingly using positive behavioral interventions and supports (PBIS) as a more effective approach to preventing and addressing student behavioral issues. School-wide PBIS refers to a system of evidence-based supports designed to enhance all students' prosocial behaviors, academic outcomes, and school climate. This proactive framework involves systematically defining, teaching, modeling, and reinforcing expected behaviors in schools, rather than waiting for misbehavior to occur before responding as was done with more traditional approaches. Ultimately, instilling school-wide PBIS will help create a school climate where appropriate behavior is the norm, leading to more positive educational experiences for all students (PBIS OSEP Technical Assistance Center, 2016b).

There have been several evaluation and quasi-experimental studies that have found PBIS to be an effective system within the schools (PBIS OSEP Technical Assistance Center, 2016a). More specifically, PBIS has been associated with several positive outcomes, including reductions in problem behaviors (e.g. Bradshaw, Mitchell, \& Leaf, 2010; Flannery, Fenning, Kato, \& McIntosh, 2013), increased academic performance (e.g. Pas \& Bradshaw, 2012; Simonsen et al., 2012), improved perception of safety (e.g. Horner et al., 2009; Kelm, McIntosh, \& Cooley, 2014), reduction in bullying behaviors (e.g. Waasdorp, Bradshaw, \& Leaf, 2012), increased attendance (e.g. Freeman et al., 2015; Pas \& Bradshaw, 2012), increased perception of teacher efficacy (e.g. Kelm \& McIntosh, 2012; Reinke, Herman, \& Stormont, 2013), improved social-emotional competence for students (e.g. Bradshaw, Waasdorp, \& Leaf, 2012; Cook, Frye, Renshaw, Slemrod, \& Lyon, 2015), and increased positive school climate and culture (e.g. 
Bradshaw, Koth, Bevans, Ialongo, \& Leaf, 2008; Caldarella, Shatzer, Gray, Young, \& Young, 2011).

Considering all of these positive outcomes that are associated with PBIS, schools have been increasingly implementing these interventions and supports within their schools. More specifically, estimates indicate that approximately 20,000 schools in the United States are implementing PBIS (Horner, 2014). However, some states have been significantly more active in implementing PBIS compared to other states. Ohio has been one state that has strongly supported PBIS initiatives, especially after the Ohio State Board of Education adopted rules and policy in 2013 that required schools to implement some form of PBIS (Ohio Department of Education, 2016). However, interpretation of this law has varied, which has led to inconsistent implementation. Fortunately, Ohio's 16 State Support Teams (SSTs) or regional resource centers have trained staff members provide PBIS trainings to school staff members in the state, which can help address these inconsistencies and ensure proper implementation. The SST trainers have been similarly trained in six different types of trainings, which include "Introductory," "Tier II/III," "Coaching," "Classroom Management," "Data Related Training," and "Train the Trainer." Regardless of the specific type of training, the trainers administer identical feedback surveys to all of the attendees following all sessions. This feedback survey consists of several items, including questions about demographic information along with additional questions that ask the attendees about their perceptions of the training session and trainers, likelihood of using the information from the session within the next four weeks, their school's level of PBIS implementation, challenges and benefits of implementing PBIS, and suggestions regarding how to improve future training sessions. The trainer also completes a cover sheet that provides more information regarding the training. These surveys are then reviewed by the trainers and serve as guides to improve upon future PBIS training sessions.

This study used archival data generated from this existing survey in order to examine the specific factors that predict the effectiveness of these training sessions. More specifically, for the purposes of this study, the effectiveness of these training sessions was defined as attendees' responses to one of the survey items that asks them to indicate their likelihood of using the information from the training session within the next four weeks. Thus, the effectiveness of these training sessions was measured by analyzing their responses to the survey item that asks attendees to indicate their level of agreement with a statement that says, "I am likely to use 
information from this session within four weeks" (i.e. item 10). Attendees responded to this item using a rating scale that ranges from 1 (Strongly Disagree) to 5 (Strongly Agree). It is important to note that research regarding professional development indicates several different definitions for "effectiveness." Several researchers have recently argued that the ultimate measure of effectiveness should be improved student learning outcomes (Hill, 2007; Guskey, 2002). Unfortunately, without information regarding changes in student learning outcomes, this study defined effectiveness as anticipated attendee changes based on available information, which is an important first step that can lead to improved student learning outcomes.

In order to examine the specific factors that predict the effectiveness of these training sessions, this study identified variables provided from other survey items on the same instrument that are significantly associated with the attendees' likelihood of using the information from the session within the next four weeks. The purpose of this study was to inform future training sessions by identifying these other pieces of information that significantly relate to the attendees' likelihood of using the information from the training within the next four week. First, however, it is important to have a general understanding of professional development. In addition, it is also important to examine previous studies that have already identified some factors that are significantly related to the effectiveness of professional development programs.

\section{Defining Professional Development}

In general, professional development refers to the participation in various types of educational experiences that are related to an individual's work. These experiences can be categorized as either formal or informal opportunities. Formal experiences involve more structured or organized activities, including attending professional conferences, seminars, workshops, or college courses. On the other hand, by definition, informal experiences are more casual and can include discussing one's work with other colleagues, conducting independent research projects, reading on one's own, learning from a peer, or observing a colleague while at work (Mizell, 2010). Clearly, an individual can complete a wide range of experiences in order to grow and develop professionally. However, regardless of whether an individual participates in formal or informal experiences, professional development in general, provides professionals with new knowledge and helps them learn how to effectively apply this information at work in the future in order to improve their overall performances and work environments (Mizell, 2010). 


\section{Purpose of Professional Development in Schools}

Teachers and other school staff members are one specific group of professionals who are required to regularly participate in professional development opportunities. Blandford (2000) outlines four main functions that professional development experiences serve within the schools. These functions include enhancing individual performance, resolving ineffective practice, beginning the groundwork for the implementation of new policy, and facilitating change. In other words, professional development experiences within schools encourage personal, team, and school development by facilitating both the acquisition and extension of knowledge, understanding, pedagogical skills, and abilities that will allow teachers and other school staff members to fulfill the many responsibilities that are necessary for high levels of school growth and positive outcomes for all students. These responsibilities include developing a wide range of practice, reflecting on experiences and current research to most effectively meet students' needs, maintaining current educational thinking to develop good practice, critically considering educational policy and how to effectively raise standards, and widening their understanding of society (Blandford). Thus, with new knowledge and training, teachers and other school staff members who participate in professional development opportunities are possibly in a position to positively impact their school climate and all of the students who attend their school. Further, when educators participate in professional development experiences that are focused on building the skills they need to address their students' educational needs, student learning and achievement theoretically should increase (Mizell, 2010).

Due to this indirect impact that professional development can have on students and their experiences in their schools, it is critical to provide effective professional development experiences to all teachers and school staff members. Effective professional development can be defined as opportunities that allow educators to develop the knowledge and skills that are necessary to address their students' learning challenges. Further, effective professional development events allow educators to easily transfer newly acquired knowledge and skills and improve their instruction to better support future students (Mizell, 2010).

Significant resources are spent on professional development opportunities each year to help educators make effective changes in their practice (Desmione, 2009). For example, the federal government spent approximately $\$ 1.5$ billion on professional development opportunities

for teachers between 2004 and 2005 (Birman et al., 2007). Continuing, high numbers of teachers 
participate in professional development activities each year. For instance, a teacher survey from 1999 indicated that $99 \%$ of respondents participated in professional development activities between during the academic year (NCES, 1999). However, despite the substantial funding provided for professional development opportunities within the U.S. school systems and the significant number of teachers who participate in these opportunities, a substantial amount of research from the past decade indicates that several of these professional development opportunities do not actually have a significant impact on student learning or lead to positive changes in teacher practices (Yoon, Duncan, Lee, Scarloss, \& Shapley, 2007). For instance, a frequently-cited meta-analysis investigated 1,300 studies of professional development programs and determined that only nine of these studies documented clear and empirical evidence of positive impacts on student achievement following professional development (Yoon, Duncan, Lee, Scarloss, \& Shapley, 2007). Furthermore, a more recent study's findings indicated that American teachers reported that many of the professional development opportunities available to them are actually not very useful to them and their work within their schools (DarlingHammond, Wei, Andree, Richardson, \& Orphanos, 2009) as events often provide information that is out-of-context and lack the necessary depth to encourage changes (Guskey, 2009). A final issue related to professional development opportunities is the general lack of knowledge regarding how to design effective programs. More specifically, most of the educators who are responsible for organizing professional development events have not had formal education in how to plan them effectively (Mizell, 2010). Given the large number of professional development opportunities that are reportedly not leading to significant positive changes, the substantial number of teachers who are not finding these experiences to be very useful when working in their schools, and the general lack of knowledge regarding how to organize effective professional development events, it is critical to examine the factors that are related to effective professional development to be able to address these issues.

\section{Factors Influencing the Effectiveness of Professional Development}

Research studies have identified several factors that significantly contribute to positive outcomes following professional development opportunities in schools. Some of these factors are briefly outlined next.

Increasing knowledge. Although it might seem obvious, professional development events must increase attendees' knowledge in order to be considered effective. In other words, 
teachers and other school staff members must first be provided with a thorough understanding of a particular concept in order to apply it in their schools and classrooms after the professional development session (Gulamhussein, 2013). More specifically, the content presented at professional development events should not consist only of generic information. Rather, teachers and other school staff members should also be provided with information that is specifically relevant to their work in order to deepen their knowledge and increase the likelihood that they will make appropriate future changes in their schools (Gulamhussin, 2013; McConnell, Parker, \& Eberhardt, 2013).

Several studies provide support for the importance of increasing attendees' knowledge in order for professional development activities to lead to lasting changes in the schools (Cohen \& Hill, 1998; Kennedy, 1998). For example, Cohen and Hill (1998) examined professional development characteristics that significantly related to students' performances on a statewide mathematics test. These researchers concluded that the scores on this mathematics test were significantly higher in schools where teachers participate in professional development experiences that focus on teaching them specific math content compared to schools with teachers who have not had professional development experiences that seek to increase their knowledge of math content (Cohen \& Hill). Similarly, Kennedy (1998) reviewed several studies related to professional development and identified significantly more positive student achievement outcomes following professional development that focuses on providing specific content compared to professional development that focuses on providing more general content. Although it is clear that increasing attendees' knowledge is an essential first step for professional development activities to be effective, this is by no means the only factor that is necessary for them to be effective. Attendees might learn information at a particular professional development event, but unless there are several other factors present to help support the application of their newly acquired knowledge in the future, teachers and other schools staff members might struggle with transferring this knowledge to their practice in the schools. These additional factors are discussed next.

Administrator support. Research also suggests administrator support significantly impacts the effectiveness of professional development events within the schools (Bechtel \& O’Sullivan, 2007; Faucette \& Graham, 1986). For example, Heck and colleagues (2008) examined the relationship between professional development and reported classroom practices in 
mathematics using questionnaires that were completed by nearly 18,000 teachers as they participated in a professional development program aimed at helping teachers implement high quality mathematics instruction. Overall, these researchers concluded that teachers' perceptions of principal support for the new instructional practices were consistently associated with changes in teachers' reported attitudes and practices in their classrooms (Heck, Banilower, Weiss, \& Rosenberg). Further, Faucette and Graham (1986) analyzed two elementary physical education teachers' attitudes and behaviors following an in-service professional development program using qualitative analyses. Towards the beginning of this study, these two physical education teachers thought that their principals were genuinely supportive of the changes discussed during the in-service program. Thus, initially, these teachers were very enthusiastic about the changes that were suggested during the program. However, as the principals lost interest in these changes over the next seven months, the teachers' enthusiasm and implementation of the changes simultaneously decrease (Faucette \& Graham). Similarly, Bechtel and O’Sullivan (2007) analyzed four case studies and examined the factors influencing secondary physical education teachers' likelihood to make changes in their programs. These researchers found that the teachers were more likely to make changes in their programs at school when they perceive high levels of support from their principals (Betchtel \& O’Sullivan). Altogether, all of these studies demonstrate the importance of administrator support for professional development opportunities to be effective and promote necessary changes in the schools.

Active learning. Additionally, research suggests professional development is more effective when it involves active learning (Garet et al., 2001; Ingvarson, Meiers, \& Beavis, 2005). Active learning involves providing opportunities for attendees to be actively engaged during the professional development program through activities such as engaging in meaningful discussion, planning for future application of recently acquired knowledge, reviewing examples of student work, and practicing newly acquired skills and obtaining feedback (Garet et al., 2001). Active learning is necessary to initiate lasting changes following professional development events because it provides teachers and other school staff members with the practice that they need to implement these changes effectively in the future. For example, one study found that when a training session simply described a skill to teachers, just ten percent of teachers effectively transferred the skill to future practice (Bush, 1984). Additionally, estimates indicate that teachers need to practice a new skill about twenty times on average in order to truly master 
it. Further, this statistic might even be an underestimate if the skill is increasingly complex (Joyce \& Showers, 2002). It is clear that teachers and other school staff members significantly benefit from active learning opportunities that give them the practice that is necessary to develop new skills.

Several research studies provide additional support for the importance of providing active learning experiences throughout professional development events (Garet et al., 2001; Ingvarson, Meiers, \& Beavis, 2005). For instance, Garet and his colleagues (2001) examined the factors that significantly impacted over 1,000 math and science teachers' learning following several professional development activities. For the purposes of their study, Garet et al. defined active learning as opportunities to observe expert teachers, be observed teaching in their own classroom, plan for future classroom implementation, review student work, give a presentation, and/or lead a discussion. The researchers found that teachers who experienced these active learning activities reported enhanced knowledge and skills and greater changes in their classroom practices following their participation in the professional development event. In addition, Ingvarson, Meiers, and Beavis (2005) surveyed over 3,000 teachers after they participated in various professional development activities in order to determine specific factors that influenced the teachers' knowledge, practice, and efficacy. Teachers reported a greater increase in knowledge and changes in their practice within schools following professional development activities that utilized active learning, which included opportunities to identify the specific areas of their practice that needed to be further developed and practice new teaching skills that were acquired during the session (Ingvarson, Meiers, \& Beavis). Overall, both of these research studies support the importance of providing attendees with active learning opportunities in order to facilitate effective professional development experiences that will lead to meaningful and positive changes.

Duration. The effectiveness of professional development is also related to the number of hours of the event along with the amount of time over which it occurs (Boyle, Lamprianou, \& Boyle, 2005; French, 1997; Garet et al., 2001; Gerard, Varma, Corliss, \& Linn, 2011; Gulamhussein, 2013). More specifically, research suggests longer professional development programs that are spread out over time can lead to more positive changes in teacher practice and improvements in student learning compared to shorter programs or one-time workshops (Whitworth \& Chiu, 2015). For example, Gerard and colleagues (2011) reviewed 43 studies 
related to professional development and found that students had more positive learning experiences and teachers experienced less instructional obstacles when teachers participated in professional development programs that were sustained beyond one year (Gerard, Varma, Corliss, \& Linn). In another study, Boyle and colleagues (2005) conducted a longitudinal analysis of professional development and teaching strategies and concluded that the majority of teachers who participated in longer term professional development activities that lasted more than two days reported changes to at least one of their teaching practices (Boyle, Lamprianou, \& Boyle).

These findings can most likely be attributed to the fact that longer programs provide teachers and other school staff members with additional time to learn the information and engage in active learning opportunities that further build their understanding (Gulamhussein, 2013). In fact, some studies argue that teachers might need approximately fifty hours of instruction and practice before mastering a new teaching strategy and implementing it in their classrooms (French, 1997). Further, having multiple professional development sessions allows trainers to better reinforce, elaborate upon, and follow-up with information that was presented during a previous session to better support teachers as they transfer the new knowledge and skills into their classrooms (Lewis, Baker, \& Helding, 2015; Whitworth \& Chiu, 2015). Finally, short, onetime workshops can often be disconnected from teachers' concerns and unrelated to the context in which teachers work, which can prevent the development of meaningful changes (Cobb et al., 2003). Altogether, it is important for professional development opportunities to be intensive and ongoing in order to provide attendees with an adequate amount of time to learn the information and practice applying it before having to do so in their classrooms.

Fostering coherence. Another factor that contributes to effective professional development programs is the degree to which the specific program fosters coherence among educators and their schools with the learning activities (Garet et al., 2001). More specifically, professional development opportunities are more effective in improving teachers' knowledge and skills when they perceive these activities to be a part of a coherent program of teacher learning. Further, coherence can involve building on what teachers have already learned, emphasizing content that is consistent with local standards and frameworks, and providing attendees with opportunities to have professional communication with colleagues who are trying to make similar changes in their practice. In other words, teachers and other school staff members are 
more likely to implement ideas from professional development programs when they view them as being consistent with movements that are already taking place within their schools (Garet et al., 2001). For example, Garet and his colleagues (2001) found that teachers who experience coherence with the learning activities at professional development sessions reported enhanced knowledge and skills and greater changes in their classroom practices following their participation in the event compared to teachers who did not experience such coherence (Garet et al.).

Timing. One final factor that should be considered is the time of year in which the professional development training occurs for teachers. Some research suggests summer is an effective time to conduct professional development events for teachers (Yoon, Duncan, Lee, Scarloss, \& Shapley, 2007). For example, Yoon and colleagues' (2007) review of professional development studies determined that several of the studies that documented positive relationships between the training and student learning outcomes were conducted during the summer months. At the same time, other professionals express concerns about summer professional development opportunities because they are not "job-embedded" and do not allow teachers to immediately transfer knowledge and skills into practice (Croft, Coggshall, Dolan, \& Powers, 2010). Thus, it is likely that summer professional development events are the most effective when they are conducted close to the beginning of the school year so that the information is relevant enough to teachers and can be properly implemented soon after. Although there were not any studies that could be identified that directly examined professional development events that are offered during other points of the academic year, there have been studies documenting significant changes experienced by teachers over the course of the year, which can influence their receptiveness to professional development opportunities. For instance, research unsurprisingly suggests teacher burnout increases throughout the academic year (Pas, Bradshaw, \& Hershfeldt, 2012), which can increase teachers' resistance to change and potentially make them unreceptive to professional development that occurs towards the end of the school year (The Edvocate, 2016). Altogether, although there seems to be some uncertainty about how timing specifically affects the effectiveness of professional development, it nevertheless may play some role, revealing one gap that the current study hopes to address. 


\section{Present Study and Hypotheses}

Altogether, this review of the literature reveals that improvement of knowledge, staff support, active learning, duration, coherence, and timing are all important factors that contribute to the effectiveness of professional development opportunities in schools. The current study examined how these six factors contribute to the effectiveness of the PBIS trainings that are being conducted in Ohio. In general, two research questions were developed for the purposes of this study. First, this study determined whether there is a relationship between each of these six factors and the effectiveness of these training sessions. Second, the study analyzed and identified the combination of factors that best predicts the effectiveness of these training sessions.

These two broad research questions guided the formation of several hypotheses along with the selection of survey items to examine in relation to the effectiveness of the PBIS trainings. Again, this study used information provided from the feedback surveys and cover sheets that attendees and trainers complete following the training sessions. More specifically, the study examined select survey items that measure constructs related to effective professional development. Given previous research regarding the variables related to the effectiveness of professional development, there were several survey items that were hypothesized to be significantly related to the attendees' likelihood of using information from the PBIS trainings in their own schools.

First, the information from the literature review reveals that in order to be effective, professional development events must significantly increase attendees' knowledge. Therefore, it was hypothesized that attendees who reported that the professional development more strongly improved their understanding of PBIS after the session will be more likely to indicate that they will use information from the training. Second, the information from the literature review indicates that administrator support significantly impacts the effectiveness of professional development within the schools. Thus, it was hypothesized that attendees will be more likely to indicate that they will use the information from the training session when an administrator from their school or district is also present at the training. Third, the information from the literature review also highlights the importance of active learning as an important component of effective professional development events. The specific items on the feedback survey do not necessarily reveal the activities that were completed during the training session, which makes it difficult to assess whether or not attendees engaged in active learning. However, the attendees were asked if 
the trainer provided feedback that helped them gain knowledge necessary to enhance their skills. Since providing feedback is one aspect of active learning, the third hypothesis was that attendees will report being more likely to use information from the session in the next four weeks if they report receiving feedback from the trainer. Fourth, the information from the literature review suggests longer professional development programs that are spread out over longer periods of time can significantly contribute to their effectiveness. Although the vast majority of PBIS training sessions would be considered relatively short professional development workshops, some of them still took place over multiple days. As a result, it was hypothesized that attendees will be more likely to indicate that they will use the information in the near future if they attend a multi-day training session. Fifth, the literature review indicates that effective professional development events involve coherence with the learning activities and connections between these activities and systems already in place at their schools. The PBIS feedback surveys ask participants to indicate their schools' level of implementation of PBIS. Thus, it was hypothesized that attendees will be more likely to implement the information from the session if their school has already started implementing PBIS. Finally, the review of the literature suggests professional development events during the summer or towards the beginning of the school year may lead to significant changes in the classroom. Thus, the final hypothesis was that attendees will report a greater willingness to use information from the session when it is offered in the summer or closer to the beginning of the school year compared to trainings conducted towards the end of the school year.

\section{Methodology}

\section{Sample}

This sample consisted of 2,855 attendees who completed a survey following one of the Ohio PBIS trainings that occurred between June 1, 2015 and May 31, 2016. Participants represented all different roles and grade levels among a diverse range of schools and school districts across Ohio. In fact, trainings were conducted in all 16 SST regions in the state, and training attendees represented urban, rural, and suburban schools. The majority of attendees were teachers $(n=1,601)$, followed by administrators $(n=641)$, related service professionals $(n=$ $533)$, and parent/community members $(n=10)$. Further, these attendees primarily worked in elementary school settings $(n=1,149)$, followed by middle schools $(n=574)$, high schools $(n=$ 
418), multiple grade levels $(n=329)$, district-level $(n=223)$, preschools $(n=73)$, and other/not applicable settings $(n=71)$. See Figures 1 and 2 for a visual representation of this breakdown.

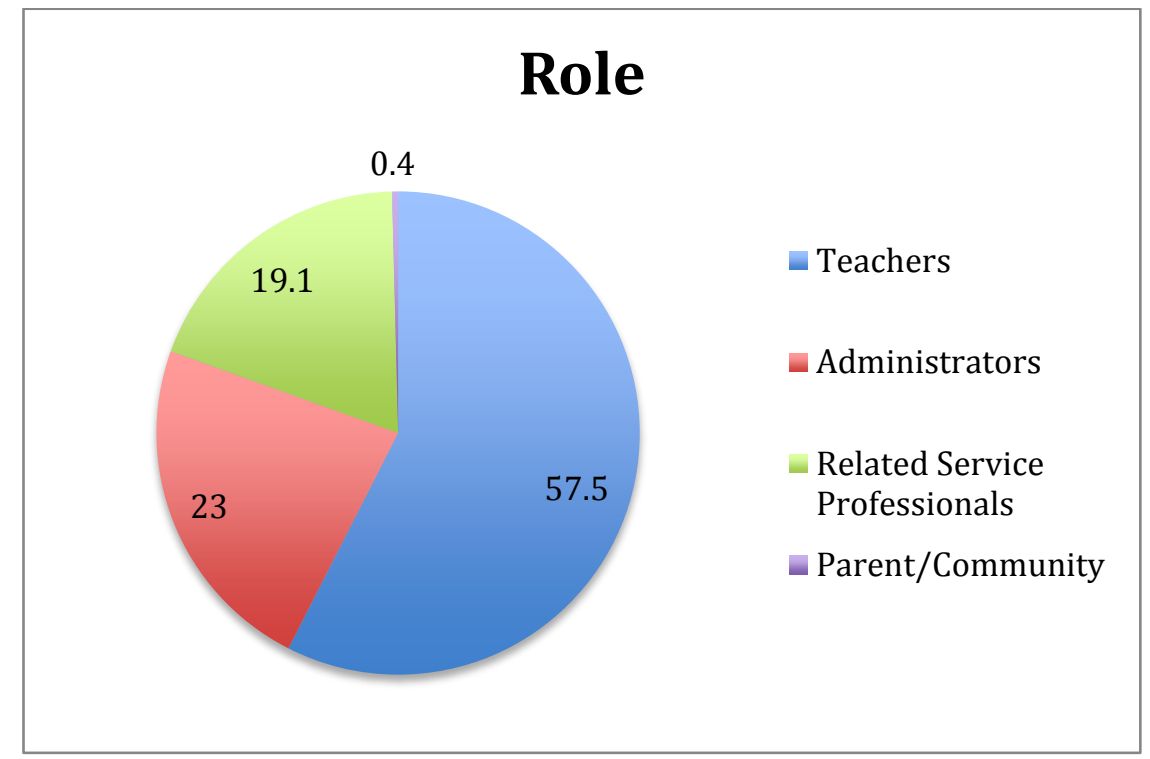

Figure 1: Role of Attendees.

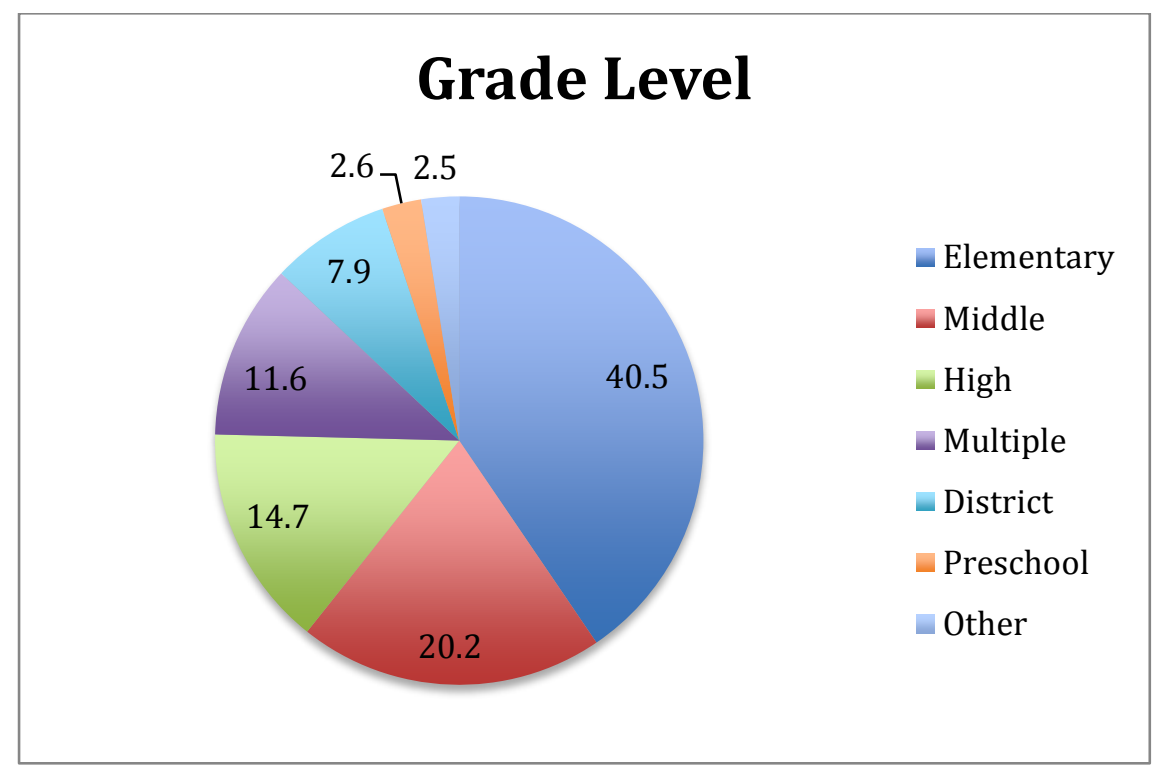

Figure 2: Grade Levels Attendees Serve.

\section{Materials}

Most of the variables that were analyzed in this study were assessed using the feedback survey that was administered to all attendees following the PBIS training (see Appendix A for items). The survey asked attendees to identify their role and grade level they serve at their 
school. In addition, the survey asked attendees to rate their level of satisfaction with the session, improvement of knowledge following the training, and likelihood that they will use the information in the next four weeks. Finally, the survey asked attendees to identify their specific perceptions of the trainer, level of knowledge both before and after the session, degree to which their district or school is already implementing PBIS, challenges they see in moving PBIS forward, benefits they anticipate in implementing PBIS, and areas for improvement. Other information that was relevant to the study was assessed using the PBIS Post-Training Submission Cover Sheet that was completed by the trainer following each session (see Appendix B). This sheet required the trainer to indicate his/her name, date of training, name of training, number of attendees, number of training sessions if it was a multi-session training series, number of surveys completed, and any additional comments.

\section{Procedures}

The study used archival data that were collected from the Ohio Department of Education following PBIS training sessions from June 1, 2015 to May 31, 2016 across the state. Attendees consisted of school staff and other community members who attended one of the PBIS trainings. These trainings consisted of an overview of PBIS along with more specific recommendations and information depending on the needs of the particular group of attendees. Specifically, the different types of training were classified as "Introductory," "Tier II/III," "Coaching," “Classroom Management," "Data Related Training," and "Train the Trainer." At the end of each session, attendees were given a survey to complete. Attendees were told that their completion of the survey items was completely voluntary. The State Support Team trainers then collected surveys from individuals who completed them. The trainers also completed a cover sheet that asked about more specific information regarding the training. The trainers then sent the surveys and cover sheet to Dr. Amity Noltemeyer at Miami University because of Miami's involvement with evaluating the effectiveness of these trainings as part of a 5-year School Climate Transformation grant from the U.S. Department of Education. Finally, data were entered into SPSS by trained graduate assistants and spot-checked for accuracy.

\section{Data Analysis}

First, initial correlations and individual predictors were identified in order to understand the individual relationships between the six factors related to professional development and 
attendees' reported likelihood of using information from training sessions within the next four weeks. These analyses were conducted using chi-square tests, Spearman's rank-order correlations, and a Kruskal Wallis $\mathrm{H}$ test depending on the nature of the specific variables that were being analyzed. Following these initial analyses, an ordinal regression was going to be conducted to develop a model for predicting attendees' likelihood of using the information in the next four weeks. However, the data did not meet the assumption for proportional odds that is necessary for this analysis. In other words, each independent variable did not have an identical effect at each cumulative split of the ordinal dependent variable. Therefore, a multinomial regression was recommended and used to identify the combination of factors that best predict the attendees' reported likelihood of using information from the training within the next four weeks.

\section{Protection of Human Subjects}

Again, the current study simply involved accessing and analyzing archival data that were already collected by the Ohio Department of Education, making the potential risk of harm for participants essentially nonexistent. In addition, participants' responses remained completely confidential during data analysis and reporting. Further, only a select group of approved individuals had access to the survey data. Finally, the IRB previously approved the access and analysis of this data as part of an ongoing data analysis project for the School Climate Transformation Grant mentioned previously, and the primary researcher was on the list of approved project personnel.

\section{Results}

Preliminary analyses included examining the study variables for normality. The data were first examined for skew and kurtosis to determine if all variables were within acceptable ranges of normality (i.e., skewness <3 and kurtosis <10; see Kline, 1998). The distribution of the outcome variable (i.e. likelihood of implementing information from session) was significantly different form normal. Thus, nonparametric procedures were used when appropriate.

Next, initial correlations and individual predictors were identified in order to understand the individual relationships between the six factors related to professional development and attendees' reported likelihood of using information from training sessions within the next four weeks. These results are reviewed next and summarized in Table 1. 


\begin{tabular}{|lll|}
\multicolumn{1}{c}{ Variable } & \multicolumn{1}{c|}{ Test } & \multicolumn{1}{c|}{ Result } \\
\hline Increase in Knowledge & Chi-Square & Significant \\
\hline Administrator Presence & Chi-Square & Nonsignificant \\
\hline Administrator Support & Spearman's Rank-Order Correlation & Significant \\
\hline Active Learning & Chi-Square & Significant \\
\hline Duration & Spearman's Rank-Order Correlation & Nonsignificant \\
\hline Coherence & Chi-Square & Significant \\
\hline Timing & Kruskal Wallis H Test & Significant \\
\hline
\end{tabular}

Table 1: Initial Correlations Summary.

First, the association between attendees' increase in knowledge about PBIS and their likelihood of using the information from the session within the next four weeks was determined by running a chi-square test. Data from items 13 (i.e. knowledge before session) and 14 (i.e. knowledge after session) were first coded into two separate groups (i.e. $1=$ positive change in knowledge after session, $0=$ no positive change in knowledge after session). Then a chi-square test was run to determine any differences in effectiveness between attendees who reported an increase in knowledge and those that did not. The relation between these variables was significant, $X^{2}(4)=74.7, p<.01$. More specifically, attendees who experienced an increase in knowledge reported a greater likelihood to use the information within the next 4 weeks.

Next, it was examined whether administrator support is positively related to attendees' likelihood of using information from the session within the next four weeks. In order to conduct this analysis, the researcher added a variable and coded for whether or not an administrator from the attendee's own building or district level was present at the training (i.e. $1=$ administrator present, $0=$ administrator not present). Then a chi-square test was conducted to examine the relationship between administrator presence at the training and the likelihood that the attendees will use the information in the near future as measured by their responses to item 10 . The relationship was not significant, $X^{2}(4)=7.15, p>.05$. In other words, attendees with and without an administrator present were equally likely to report using the information within the next 4 weeks. As a follow-up analysis, the researcher looked at the relationship between participants' reported likelihood of using the information from the session and their administrators' reported likelihood of using the information from the session when an administrator was present. This analysis was completed using a Spearman's rank-order 
correlation, and the relationship was found to be positive and significant $\left(r_{s}=.49, p<.01\right)$. In other words, participants were reportedly more willing to use the information when administrators in their building or district were also willing to use the information. It is important to note that parents and community members were included in this analysis because these individuals were also working in schools with these administrators.

Continuing, the researcher examined the relationship between the effectiveness of the trainings and the use of active learning as measured by whether or not the trainer reportedly provided attendees with feedback (i.e. $1=$ feedback was given, $0=$ feedback was not given). To measure this relationship, a chi-square test was run to determine any differences in effectiveness between attendees who reported receiving feedback and those that did not. The relation between these variables was significant, $X^{2}(4)=99.26, p<.01$. More specifically, attendees who received feedback reported a greater willingness to use the information from the session. In addition, the researcher determined the relationship between the duration of trainings and attendees' likelihood of using the information from the session within the next four weeks by running a Spearman's rank-order correlation. More specifically, the researcher found the correlation between the duration of trainings as measured by the number of days of each training and the attendees' responses to item 10, which again, assessed their likelihood of using the information in the next four weeks. The correlation was positive but not significant $\left(r_{s}=.003, p\right.$ $=.89)$.

Next, the researcher analyzed the relationship between the attendees' likelihood of using the information in the next four weeks and the coherence between learning activities at the training and structures currently in place at their schools. Again, the researcher measured coherence by analyzing the attendees' responses regarding their schools' current level of implementation of PBIS (i.e. survey item 15). There are four response options to this question that range from 1 (yes, currently implementing) to 4 (we have no plans for implementation), and these responses were coded in a dichotomous way to form two independent groups (i.e. $1=$ school currently is implementing, $0=$ school currently is not implementing). The researcher then conducted a chi-square test to determine if attendees' likelihood of using the information is related to their schools' current level of implementation. The relation between these variables was significant, $X^{2}(12)=53.9, p<.01$. More specifically, attendees who worked in schools 
already implementing PBIS were more likely to plan on using information from the session within the next 4 weeks.

Finally, a Kruskal Wallis H test was used to determine any group differences in effectiveness between the months in which the training occurs. Since the researcher was primarily interested in differences between general time periods during the year, rather than month-by-month differences, training dates were coded into four separate groups that reflect four general points throughout the year. Specifically, the first group consisted of trainings that occurred during the summer months (i.e. June, July, and August); the second group consisted of trainings that occurred during the beginning of the school year (i.e. September, October, and November); the third group consisted of trainings that occurred during the middle of the school year (i.e. December, January, and February); and the fourth group consisted of trainings that occurred towards the end of the school year (i.e. March, April, and May). Results from a Kruskal Wallis $\mathrm{H}$ test revealed significant group differences $(\mathrm{H}=16.02, p<.01)$. Follow-up pairwise comparisons indicated significant differences between summer trainings $(M=4.13, S D=1.03)$ and mid-year trainings $(M=4.41, S D=.71)$, summer trainings $(M=4.13, S D=1.03)$ and beginning of the year trainings $(M=4.4, S D=.82)$, and end of the year trainings $(M=4.31, S D$ $=.84)$ and beginning of the year trainings $(M=4.4, S D=.82)$. In other words, the most consistent finding from these follow-up comparisons indicated that trainings were most effective when they were offered at the beginning of the academic year.

\section{Multinomial Regression}

Next, a multinomial regression was used to identify the combination of factors that best predicted attendees' reported likelihood of using information from the training within the next four weeks. It is important to note that when interpreting the results from this analysis, a corrected significance value of .01 was used as the critical value. Due to the large number of statistical tests being run during this analysis and the subsequent increased Type I error, it is recommended that a corrected value in which .05 is divided by the total number of predictor variables be used (Tabatchnick \& Fidell, 2007). Administrator support and number of sessions were variables that were excluded from this analysis because they were not significantly correlated with effectiveness of the trainings. After excluding these variables, the predictor variables in the multinomial regression were increase in knowledge, date of training, coherence, and feedback. 
Overall, the model was significantly different from the intercept-only model, $X^{2}(24)=$ $243.09, p<.01$. More specifically, the likelihood ratio test determined the contribution of each of the predictor variables to the outcome variable, and the date of the training $\left(X^{2}=61.71, p<.01\right)$, coherence $\left(X^{2}=37.32, p<.01\right)$, feedback $\left(X^{2}=74.97, p<.01\right)$, and increase in knowledge $\left(X^{2}=\right.$ $64.16, p<.01)$ all were found to make significant contributions to the model. In addition, the model has adequate accuracy as it predicted responses in $55.4 \%$ of cases, which exceeds the proportional-by-chance accuracy rate for this data.

\section{Discussion}

Overall, most of the findings aligned with this study's hypotheses and professional development literature. As predicted, the effectiveness of the trainings was significantly related to the incorporation of feedback, level of coherence between learning activities at the training and structures currently in place at attendees' schools, attendees' increase in knowledge, and date of the training. Interestingly, the presence of an administrator from an attendee's building or district did not have a significant relationship with their likelihood of using the information from the session within the next 4 weeks. However, in a follow-up analysis, the administrators' likelihood of using the information was significantly related to the attendees' likelihood of using the information from within their building or district.

Finally, contrary to one of the initial hypotheses, the other variable that did not have a significant relationship with the effectiveness of the sessions was the duration of the trainings as measured by the number of days each one occurred. However, this finding is likely due to the fact that the measure of duration was really a proxy of duration given the varying lengths of single- and multi-day trainings. For example, multi-day trainings did not necessarily last longer than single-day trainings in terms of the total number of hours. In other words, multi-day trainings could have actually been shorter programs even though they were spread out over more days compared to a single-day training that lasted an entire day. Unfortunately, given the limited amount of information provided on the feedback surveys, there was no way to code for the number of hours and capture the true length of each training session. Again, research suggests that longer programs provide teachers and other school staff members with additional time to learn the information and engage in active learning opportunities that further build their 
understanding of the content (Gulamhussein, 2013). Altogether it is likely that the findings related to duration were impacted given the variable used to measure this construct might not have adequately captured the true length of sessions and instead provided more information related to latency.

Furthermore, there is some research to suggest that simply extending the length of a training or spreading a series of trainings out over a period of time is not necessarily going to be effective without careful consideration of such decisions (e.g. Landesman et al., 2011). In other words, trainings must find a delicate balance between spaced and massed practice when delivering professional development to teachers specifically. That is, when designing professional development events for educators, trainers must be very strategic when making decisions regarding the length and frequency of trainings. For example, Landesman and colleagues (2011) manipulated the spacing of professional development coaching provided to teachers while holding the overall amount of training constant. These researchers found significant classroom gains following 20 full days of coaching over the span of five weeks compared to one full day of coaching per week over the span of 20 weeks (Landesman et al.). Therefore, defining and measuring effective duration for professional development events is difficult to do, and it is likely that the current study did not adequately capture this variable.

\section{Implications for Future Trainings}

These findings have several implications for future PBIS trainings. Before discussing these implications, it is important to first note that most attendees responded positively to the trainings. For example, the vast majority of attendees found these trainings to be useful, as $90 \%$ of attendees either strongly agreed or agreed with the survey item that stated that they were likely to use the information from the session within the next 4 weeks. Therefore, the following recommendations are intended to be used to make these PBIS trainings more effective than they clearly already are. The following considerations are organized by each variable that was found to be individually related to the effectiveness of the trainings. Trainers can use this information as they prepare for future sessions by addressing each variable individually while also considering the specific combination of factors that best fit the regression model (i.e. increase in knowledge, coherence, feedback, and date of training).

Increasing knowledge. Attendees reported being more willing to use the information from each training when they also experienced an increase in their knowledge following the 
session. Therefore, it is critical for trainers to help attendees learn and acquire new knowledge. One practical way trainers can ensure that this increase in knowledge happens is by providing a needs assessment prior to a training where attendees can share ideas about what they know and what they are interested in learning more about at the training. The trainers can then use this information to fine-tune their presentations in order to best fit the needs of the audience and address topics that attendees want to know more about. Interestingly, the feedback survey has an open-ended question for attendees to identify areas of improvement for future trainings, and a common response involves wanting trainers to cover new information because they find some material to be redundant with what they already know. Conducting a needs assessment is one technique that has been successfully incorporated into other professional development programs (Lee, 2005) and can help trainers better understand how to most effectively increase attendees' knowledge.

Administrator support. The mere presence of a building or district administrator was not significantly related to attendees' reported willingness to use the information from the session within the next 4 weeks. However, administrators' willingness to use the information from the session was significantly related to attendees' willingness to use the information. Therefore, it could be helpful for trainers to specifically encourage administrator commitment to PBIS during the training. For example, the trainer might meet with all of the administrators as a group for a few minutes before or during the training to communicate the significant impact their attitudes can have on the actions and attitudes of other staff members in their buildings. In addition, the trainer could provide some time for the administrators to work together as a group to brainstorm specific actions they can take to support educators as they implement PBIS in their classrooms. Finally, it could also be beneficial for trainers to specifically meet with administrators to discuss any resistance to PBIS because overcoming resistance at the administration level may have positive ripple effects for other staff members who are impacted by their administrator's attitudes and actions.

Active learning. Given the limited information provided on the feedback surveys, active learning had to be measured in a very specific way. Although active learning can encompass a wide variety of activities, this study defined it as receiving feedback from the trainer. As predicted, attendees reported a greater willingness to use information from the session when they also received feedback from the trainer. Therefore, trainers should make an effort to provide 
feedback to attendees whenever possible during future trainings. More specifically, research suggests effective feedback is goal-referenced, actionable, user-friendly, and timely (Association for Supervision and Curriculum Development, 2012).

Providing feedback is clearly an important aspect of active learning, but active learning can be incorporated in future trainings in other ways as well. For example, job-embedded coaching has been found to be related to increases in educators' perceived skills relative to RtI (Castillio et al., 2016). Although it might not be feasible for trainers to provide such intensive coaching to attendees, it is still something that can be considered and developed using school staff with more extensive knowledge and training in PBIS (i.e. school psychologist, school counselor, etc.). Additional active learning activities can include engaging attendees in meaningful discussions about planning for future application of recently acquired knowledge (Garet et al., 2001). Therefore, it could be helpful to provide time at the end of a training session for individuals from the same building to meet and talk about how to successfully apply information from the training at their school specifically.

Fostering coherence. Again, attendees reported a greater willingness to use the information from the session within the next 4 weeks when there was coherence between the training content and movements already taking place within their buildings as measured by whether or not the school is currently implementing PBIS. Although a trainer has very little control over whether or not attendees' schools are currently implementing PBIS, there are other ways trainers can foster coherence. For example, conducting a needs assessment can provide trainers with information regarding how attendees are currently implementing PBIS in their buildings. Trainers can then meet attendees where they are and include information about how to make these practices more effective.

Timing. There were several significant differences between trainings taking place at different points throughout the year. The most consistent pattern involved attendees reporting a greater willingness to use information from a session following trainings that took place at the beginning of the academic year during the months of September, October, or November. For instance, attendees reported being significantly more likely to use the information following beginning of the academic year trainings compared to trainings that took place during the summer and at the end of the year. Therefore, it seems trainings could be particularly effective if they occur at the beginning of the school year. This is not to say that trainings cannot be effective 
at other points during the year, but trainers should just be aware of potential barriers that exist at these times and consider potential ways to most effectively overcome them. For example, when trainings are conducted near the end of the academic year, trainers may want to have the attendees set specific goals for how they will apply the information in the subsequent school year, and then follow-up during the first month of school to support putting that plan into action.

\section{Implications for School Psychologists}

This study has important implications for school psychologists specifically. As professionals who often play a role in organizing and leading professional development events in schools, school psychologists can consider these findings in order to provide effective professional development training for educators. By carefully considering the timing, duration, content, and delivery, school psychologists can more effectively organize events that will more likely lead to meaningful changes in their buildings. In addition, as professionals who often receive some graduate training in PBIS, school psychologists are also in a unique position to bridge the gap between research and practice with regard to PBIS. This study specifically highlights some ways that school psychologists can train staff members and support them in learning how to effectively implement PBIS in their schools.

\section{Limitations}

This study provides general information regarding professional development along with specific insight about how educators can be effectively trained in PBIS. However, there are several limitations that need to be considered. First, the outcome variable only assessed attendees' reported likelihood of using information from the session within the next 4 weeks. Without any follow-up work with these attendees, it is impossible to determine if educators actually implemented such changes. Therefore, future studies should measure changes that actually occur following a session in order to better understand the effectiveness of these trainings. Second, due to the nature of the variables of interest, causal relationships cannot be assessed. Again, the predictor and outcome variables are all being measured on the survey simultaneously, so it is impossible to determine if the predictors are causing changes in attendees' willingness to use information from the session within the next 4 weeks. Finally, there is a limitation with the specific regression analysis that was used in this study. Specifically, assessing model fit is not as well developed for multinomial regressions as in linear regression 
methods (Petrucci, 2009). However, due to the nature of the data, this was the best analysis to use as explained previously.

\section{Future Directions}

In addition to the ideas already presented in the previous section, there are other future directions to consider. First, given there are six different types of trainings offered through the SSTs, future studies can examine whether the relationships between effectiveness and the professional development variables vary by training type. If meaningful differences exist, this differentiation can help trainers more effectively plan a session based on the type of training. Second, future research will benefit from gathering more data after training sessions occur and examining the specific conditions and structures that are necessary for changes to occur.

Altogether, this study provides information regarding planning effective professional development events in general. This information can be applied in almost any setting where individuals are being trained in making meaningful changes. This study also specifically focuses on how to effectively train educators in PBIS, which can be helpful for both trainers as they prepare for future PBIS trainings and also school psychologists and other professionals who are often responsible for organizing and leading professional development events. Given all of the positive outcomes associated with PBIS and the increasing number of schools using it, it is critical that educators understand how to effectively implement PBIS with integrity. By carefully considering some of the variables explored in this study, PBIS trainings will hopefully lead to more meaningful changes in the schools that contribute to positive academic and behavioral outcomes for all students. 


\section{References}

Association for Supervision and Curriculum Development. (2012). Seven keys to effective feedback. Retrieved from http://www.ascd.org/publications/educationalleadership/sept12/vol70/num01/Seven-Keys-to-Effective-Feedback.aspx

Bechtel, P. A., \& O'Sullivan, M. (2007). Enhancers and inhibitors of teacher change among secondary physical educators. Journal of Teaching in Physical Education, 26, 221-235.

Birman, B., Le Floch, K. C., Klekotka, A., Ludwig, M., Taylor, J., Walters, K., . . O’Day, J. (2007). State and local implementation of the No Child Left Behind Act: Vol. 2 Teacher quality under NCLB: Interim report. Washington, DC: U.S. Department of Education; Office of Planning, Evaluation, and Policy Development; Policy and Program Studies Service.

Blandford, S. (2000). Managing professional development in schools. New York: Routledge.

Boyle, B., Lamprianou, I., \& Boyle, T. (2005). A longitudinal study of teacher change: What makes professional development effective? Report of the second year of the study. School effectiveness and school improvement, 16(1), 1-27.

Bradshaw, C. P., Koth, C. W., Bevans, K. B., Ialongo, N., \& Leaf, P. J. (2008). The impact of School-Wide Positive Behavioral Interventions and Supports (PBIS) on the organizational health of elementary schools. School Psychology Quarterly, 23(4), 462.

Bradshaw, C. P., Koth, C. W., Thornton, L. A., \& Leaf, P. J. (2009). Altering school climate through school-wide Positive Behavioral Interventions and Supports: Findings from a group-randomized effectiveness trial. Prevention Science, 10(2), 100-115. doi:10.1007/s11121-008-0114-9

Bradshaw, C. P., Mitchell, M. M., \& Leaf, P. J. (2010). Examining the effects of schoolwide positive behavioral interventions and supports on student outcomes results from a randomized controlled effectiveness trial in elementary schools. Journal of Positive Behavior Interventions, 12(3), 133-148. doi:10.1177/1098300709334798

Bradshaw, C. P., Waasdorp, T. E., \& Leaf, P. J. (2012). Effects of school-wide positive behavioral interventions and supports on child behavior problems. Pediatrics, 130(5), 1136-1145. doi:10.1542/peds.2012-0243

Bush, R.N. (1984). Effective staff development in making schools more 
effective: Proceedings of three state conferences. San Francisco, CA: Far West Laboratory.

Caldarella, P., Shatzer, R. H., Gray, K. M., Young, K. R., \& Young, E. L. (2011). The effects of school-wide positive behavior support on middle school climate and student outcomes. RMLE Online, 35(4), 1-14. doi:10.1080/19404476.2011.11462087

Castillo, J. M., March, A. L., Tan, S. Y., Stockslager, K. M., Brundage, A., Mccullough, M., \& Sabnis, S. (2016). Relationships between ongoing professional development and educators' perceived skills relative to RtI. Psychology in the Schools, 53(9), 893-910.

Cobb, P., McClain, K., Lamberg, T.S., \& Dean, C. (2003). Situating teachers' instructional practices in the institutional setting of the school and district. Educational Researcher, 32 (6), 13-24.

Cohen, D. K., \& Hill, H. C. (1998). Instructional policy and classroom performance: The mathematics reform in California (RR-39). Philadelphia: Consortium for Policy Research in Education.

Cook, C. R., Frye, M., Slemrod, T., Lyon, A. R., Renshaw, T. L., \& Zhang, Y. (2015). An integrated approach to universal prevention: Independent and combined effects of PBIS and SEL on youths' mental health. School Psychology Quarterly, 30(2), 166-183. doi:10.1037/spq0000102

Croft, A., Coggshall, J. G., Dolan, M., \& Powers, E. (2010). Job-Embedded Professional Development: What It Is, Who Is Responsible, and How to Get It Done Well. Issue Brief. National Comprehensive Center for Teacher Quality.

Darling-Hammond, L., Wei, R. C., Andree, A., Richardson, N., \& Orphanos, S. (2009). Professional learning in the learning profession. Washington, DC: National Staff Development Council.

Desimone, L. M. (2009). Improving impact studies of teachers' professional development: Toward better conceptualizations and measures. Educational Researcher, 38(3), 181-199.

Faucette, N., \& Graham, G. (1986). The impact of principals on teachers during in-service education: A qualitative analysis. Journal of Teaching in Physical Education, 5(2).

Flannery, K. B., Fenning, P., Kato, M. M., \& McIntosh, K. (2014). Effects of school-wide positive behavioral interventions and supports and fidelity of implementation on problem behavior in high schools. School Psychology Quarterly, 29(2), 111-124. 
doi:10.1037/spq000039

Freeman, J., Simonsen, B., McCoach, D. B., Sugai, G., Lombardi, A., \& Horner, R. (2015). Relationship between school-wide positive behavior interventions and supports and academic, attendance, and behavior outcomes in high schools. Journal of Positive Behavior Interventions, 41-51. doi:10.1177/1098300715580992

French, V. W. (1997). Teachers must be learners, too: Professional development and national teaching standards. NASSP bulletin, 81(585), 38-44.

Garet, M. S., Porter, A. C., Desimone, L., Birman, B. F., \& Yoon, K. S. (2001). What makes professional development effective? Results from a national sample of teachers. American Educational Research Journal, 38(4), 915-945.

Gerard, L. F., Varma, K., Corliss, S. B., \& Linn, M. C. (2011). Professional development for technology-enhanced inquiry science. Review of Educational Research, 81(3), 408-448.

Gulamhussein, A. (2013). Teaching the teachers: Effective professional development in an era of high stakes accountability. Center for Public Education, 1-47.

Guskey, T. R. (2002). Professional Development That Works: What Makes Professional Development Effective? Phi Delta Kappan. Retrieved August 29, 2009 from http://www.accessmylibrary.com/coms2/summary_0286-23450293_ITM

Guskey, T. R. (2009). What Works in Professional Development? Phi Delta Kappan, March: 495-500.

Heck, D. J., Banilower, E. R., Weiss, I. R., \& Rosenberg, S. L. (2008). Studying the effects of professional development: The case of the NSF's local systemic change through teacher enhancement initiative. Journal for Research in Mathematics Education, 113-152.

Hill, H.C. (2007). Learning in the Teaching Workforce. The Future Of Children, Spring, 17 (1): 111-127.

Horner, R. H. (July, 2014). Using PBIS to make schools more effective and equitable. Paper presented at the Southern Region Student Wellness Conference, Indian Wells, CA.

Horner, R. H., Sugai, G., Smolkowski, K., Eber, L., Nakasato, J., Todd, A. W., \& Esperanza, J. (2009). A randomized, wait-list controlled effectiveness trial assessing school-wide positive behavior support in elementary schools. Journal of Positive Behavior Interventions, 1-12. doi:10.1177/1098300709332067 
Ingvarson, L., Meiers, M., \& Beavis, A. (2005). Factors affecting the impact of professional development programs on teachers' knowledge, practice, student outcomes \& efficacy. Education Policy Analysis Archives, 13(10).

Joyce, B. \& Showers, B. (2002). Student achievement through staff development. Alexandria, VA: Association for Supervision and Curriculum Development.

Kelm, J. L., \& McIntosh, K. (2012). Effects of school- wide positive behavior support on teacher self- efficacy. Psychology in the Schools, 49(2), 137-147. doi:10.1002/pits.20624

Kelm, J. L., McIntosh, K., \& Cooley, S. (2014). Effects of implementing school-wide positive behavioural interventions and supports on problem behaviour and academic achievement in a Canadian elementary school. Canadian Journal of School Psychology, 195-212. doi:10.1177/0829573514540266

Kennedy, M. M. (1998). Form and substance in in-service teacher education (Research Monograph No. 13). Arlington, VA: National Science Foundation.

Kline, R. (1998). Principles and practice of structural equation modeling. New York: The Guilford Press.

Landesman Ramey, S., Crowell, N. A., Ramey, C. T., Grace, C., Timraz, N., \& Davis, L. E. (2011). The dosage of professional development for early childhood professionals: How the amount and density of professional development may influence its effectiveness. In The Early Childhood Educator Professional Development Grant: Research and Practice (pp. 11-32). Emerald Group Publishing Limited.

Lee, H. J. (2005). Developing a professional development program model based on teachers' needs. Professional Educator, 27, 39-49.

Lewis, E. B., Baker, D. R., \& Helding, B. A. (2015). Science teaching reform through professional development: Teachers' use of a scientific classroom discourse community model. Science Education, 99(5), 896-931.

McConnell, T. J., Parker, J. M., \& Eberhardt, J. (2013). Problem-based learning as an effective strategy for science teacher professional development. Clearing House: A Journal of Educational Strategies, Issues, and Ideas, 86(6), 216-223.

Mizell, H. (2010). Why Professional Development Matters. Learning Forward. 504 South Locust Street, Oxford, OH 45056. 
National Center for Education Statistics. (1999). Teacher Quality: A Report on the Preparation and Qualifications of Public School Teachers, NCES 1999-080. U.S. Department of Education/OERI.

Ohio Department of Education. (2016). Policy: Positive behavior interventions and support and restraint and seclusion. Retrieved from http://education.ohio.gov/Topics/Other- Resources/School-Safety/Building-BetterLearning-Environments/Policy-Positive-Behavior-Interventions-and-Support

Pas, E. T., \& Bradshaw, C. P. (2012). Examining the association between implementation and outcomes. The Journal of Behavioral Health Services \& Research, 39(4), 417-433. doi:10.1007/s11414-012-9290-2

Pas, E. T., Bradshaw, C. P., \& Hershfeldt, P. A. (2012). Teacher-and school-level predictors of teacher efficacy and burnout: Identifying potential areas for support. Journal of School Psychology, 50(1), 129-145.

Petrucci, C. J. (2009). A primer for social worker researchers on how to conduct a multinomial logistic regression. Journal of Social Service Research, 35(2), 193-205.

Positive Behavioral Interventions \& Supports OSEP Technical Assistance Center (2016a). Evaluation studies. Retrieved from https://www.pbis.org/research/primary/evaluationstudies

Positive Behavioral Interventions \& Supports OSEP Technical Assistance Center (2016b). What is school-wide PBIS? Retrieved from https://www.pbis.org/school

Reinke, W. M., Herman, K. C., \& Stormont, M. (2013). Classroom-level positive behavior supports in schools implementing SW-PBIS identifying areas for enhancement. Journal of Positive Behavior Interventions, 15(1), 39-50. doi:10.1177/1098300712459079

Simonsen, B., Eber, L., Black, A. C., Sugai, G., Lewandowski, H., Sims, B., \& Myers, D. (2012). Illinois statewide positive behavioral interventions and supports evolution and impact on student outcomes across years. Journal of Positive Behavior Interventions, 14(1), 5-16. doi:10.1177/1098300711412601

Tabatchnick, B. G., \& Fidell, L. S. (2007). Using multivariate statistics (5th ed., pp. 481-498). Boston: Pearson Education, Inc.

The Edvocate (2016). Ask an expert: The effects of teacher burnout. Retrieved from http://www.theedadvocate.org/ask-dr-lynch-the-effects-of-teacher-burnout/ 
Waasdorp, T. E., Bradshaw, C. P., \& Leaf, P. J. (2012). The impact of schoolwide positive behavioral interventions and supports on bullying and peer rejection: A randomized controlled effectiveness trial. Archives of Pediatrics \& Adolescent Medicine, 166(2), 149156. doi:10.1001/archpediatrics.2011.755

Whitworth, B. A., \& Chiu, J. L. (2015). Professional development and teacher change: The missing leadership link. Journal of Science Teacher Education, 26(2), 121-137.

Yoon, K. S., Duncan, T., Lee, S. W.-Y., Scarloss, B., \& Shapley, K. (2007). Reviewing the evidence on how teacher professional development affects student achievement (Issues \& Answers Report, REL 2007-No. 033). Washington, DC: U.S. Department of Education, Institute of Education Sciences, National Center for Education Evaluation and Regional Assistance, Regional Educational Laboratory Southwest. Retrieved from http://ies.ed.gov/ncee/edlabs 
Appendix A: PBIS Survey

\section{Appendices}

Q1 What is the title of the presentation?

Q2 Who was it presented by?

Q3 What was the date of training?

Q4 What is your district (if applicable)?

Q5 What is your building (if applicable)?

Q6 What is your role?

口 Administrator (1)

a Teacher (2)

口 Related Services (3)

口 Parent/community member (4)

Q7 What grade level do you serve?

口 District (1)

口 Preschool (2)

alementary (3)

口 Middle/Jr. High (4)

$\square$ High School (5)

口 Other/NA (6) 
Q8 I am very satisfied with this session: (please check one)

O Strongly Disagree (1)

O Disagree (2)

O Neutral (3)

O Agree (4)

O Strongly Agree (5)

Q9 This session improved my knowledge and understanding of PBIS as a process for implementing a multi-tiered behavioral framework: (please check one)

O Strongly Disagree (1)

O Disagree (2)

O Neutral (3)

O Agree (4)

O Strongly Agree (5)

Q10 I am likely to use information from this session within 4 weeks: (please check one)

O Strongly Disagree (1)

O Disagree (2)

O Neutral (3)

O Agree (4)

O Strongly Agree (5)

Q11 Explain how you will use information within 4 weeks:

Q12 The facilitator(s): (please check ALL that apply)

口 Was/were knowledgeable about the session content

口 Presented information in a way that helped me learn

口 Was/were available to address my questions

口 Was/were respectful to participants

P Provided feedback that helped me gain knowledge necessary to enhance my skills 
Q13 Please rate your level of knowledge on the topics covered before the session.

Very low (1)

Low (2)

O Medium (3)

O High (4)

Very High (5)

Q14 Please rate your level of knowledge on the topics covered after the session.

Very low (1)

$\bigcirc \operatorname{Low}(2)$

Medium (3)

O High (4)

Very High (5)

Q15 Is your district or school implementing PBIS or a similar multi-tiered behavioral framework?

Yes, currently implementing (1)

No, but will implement this academic year (2)

No, but will implement next academic year (3)

No plans to begin implementation this or next academic year (4)

Q16 Based on today's professional development session, what challenges do you see in moving this work forward in your work setting?

Q17 Based on today's professional development session, what opportunities/benefits do you anticipate in moving this work forward in your work setting? 
Q18 What from today could be improved for future professional development offerings? E.g., Structure of professional development, content, activities 
Appendix B: PBIS Post-Training Survey Submission Cover Sheet

TRAINER NAME:

DATE OF TRAINING:

NAME OF TRAINING:

NUMBER OF ATTENDEES:

If a MULTI-Session Training SeRIES, \# OF SeSSIONS:

NUMBER OF SURVEYS INCLUDED IN THIS PACKET:

COMMENTS: 